\title{
La Educación Patrimonial y la Formación Docente desde la Transcomplejidad
}

\author{
Heritage education and teacher education from the Transcomplejidad
}

\author{
Milagros Elena Rodríguez*
}

\section{RESUMEN}

En éste artículo de investigación, se muestra una indagación con el enfoque de la hermenéutica comprensiva, diatopica y ecosófica como transmétodo de construcción teórica; visionado ejes teóricos de la Educación Patrimonial Transcompleja (EPT) y la formación docente transcompleja; con categorías constitutivas como: cultura, transcomplejidad, Educación Patrimonial, EPT, formación docente, ecosofia y transmodernidad, entre otras. Atendiendo autores como Rodríguez (2017), García (2012), entre otros. Se tienen en el rizoma final nuevas miradas en los constructores de la EPT y la formación docente, la transcomplejidad del docente con la EPT lleva a romper con la creencia que la totalidad de la cultura se limita a la realidad que vemos y percibimos y comprende que es mucho la que está por descubrir, por reconstruir por valorizar los patrimonios culturales excluidos, más aún la valorización de los que tenemos, el docente rompe con el lenguaje repetitivo y excesiva cientificidad que nos inscribe en su limitada perspectiva de la cultura y se abre a la diversidad cultural a las culturas olvidadas y desgarra el caparazón instalado en sus vidas transculturizada y por último romper con un modo de vida esclerotizado y convencional donde cree que adaptarse a culturas o estereotipos de estas, en apariencia más avanzadas, que no son nuestras lo hace mejor persona.

Palabras clave: EPT, transcomplejidad, transmodernidad, formación docente, ecosofia.

RECIBIDO: Abril 2018

ACEPTADO: Julio 2018

\footnotetext{
* Postdoctora en Ciencias de la Educación, Doctora en Patrimonio Cultural, Doctora en Innovaciones Educativas, Magíster Scientiaurum en Matemáticas, Licenciada en Matemáticas, Docente Investigadora Titular, Universidad de Oriente, Departamento de Matemáticas, con más de 100 publicaciones entre libros, capítulos y artículos. Tutora de Pregrado y Postgrado. Venezuela. Correo electrónico: melenamate@ hotmail.com blog: http://melenamate.blogspot.com/
} 


\section{ABSTRACT}

In this research article, an investigation with the approach of comprehensive, diatopic and ecosophic hermeneutics as a transmethod of theoretical construction is shown; the theoretical axes of the Transcomplex Heritage Education (EPT) and the transcomplex teacher training; with constitutive categories such as: culture, transcomplexity, Heritage Education, EFA, teacher training, ecosophy and transmodernity, among others. Attending authors as Rodriguez (2017), Garcia (2012), among others. We have in the final rhizome new views in the constructors of the EFA and teacher training, the transcomplexity of the teacher with EFA leads to break with the belief that the totality of culture is limited to the reality we see and perceive and understand that there is much that is yet to be discovered, to rebuild by valuing the excluded cultural patrimonies, and even more to value those that we have, the teacher breaks with the repetitive language and excessive scientificity that inscribes us in its limited perspective of culture and opens up to cultural diversity to forgotten cultures and tears the shell installed in their lives transcultured and finally break with a sclerotic and conventional way of life where they believe that adapting to cultures or stereotypes of these, apparently more advanced, that are not ours does better person.

Keywords: EPT, transcomplexity, transmodernity, teacher education, ecosophy.

\section{Rizoma Inicial: Andamiaje transmetodológico e introducción a las concepciones constitutivas de la indagación}

La Educación Patrimonial, se ha delineado desde los diseños curriculares, las leyes orgánicas de educación, las constituciones venezolanas, y convenios internacionales, vinculada al proyecto de nación propuesta desde el modelo económico imperante, con la finalidad de definir la identidad de los venezolanos, y las expresiones de ciudadanía. En general, forma un docente reduccionista, limitado a los conocimientos de la disciplina, acrítico. Un individuo ahistórico, cuya vida escolar solo había tenido sentido en sus primeros niveles, el leer, escribir y contar. En las universidades se enseñaba filosofía e idiomas, pero aisladas de las otras disciplinas. Pretendía la formación de un ciudadano técnico, exclusivamente para el trabajo.

La presente indagación usa la hermenéutica comprensiva, diatopica y ecosófica como transmétodo de construcción teórica para visionar ejes teóricos de la Educación Patrimonial Transcompleja y la formación docente transcompleja trata de comprender desde la transcomplejidad la Educación Patrimonial y la formación docente; con categorías constitutivas como: cultura, transcomplejidad, Educación Patrimonial, EPT, formación docente, ecosofia y transmodernidad, entre otras. En este caso hermenéutica comprensiva, diatopica y ecosófica le permite a la investigadora: interpelar los territorios temáticos del conocimiento, la imaginación creadora, la actitud transvisionaria, la irreverencia frente a lo conocido, los modos de interrogar la 
realidad, la criticidad en el hermeneuta (la autora), la libertad de pensamiento entre otras.

Santos (2002) afirma que la hermenéutica diatópica consiste en "elevar la conciencia de la incompletud a su máximo posible participando en el diálogo, como si estuviera con un pie en una cultura y el otro en la restante. Aquí yace su carácter diatópico". (p.70). Desde este carácter se respeta la diversidad cultural; tal cual Santos (1998) respalda el hecho de que la hermenéutica diatópica "no sólo requiere un tipo de conocimiento diferente, sino también un proceso diferente de creación de conocimiento. Requiere la creación de un saber colectivo y participativo basado en intercambios cognitivos y emotivos iguales, un conocimiento como emancipación, más que un conocimiento como regulación" (p.30).

En tanto que Balza (2016) afirma que la hermenéutica ecosofica "designa asumir una perspectiva ética y comprensiva de las relaciones entre los seres humanos en su interacción cultural con el planeta tierra, lo cual deviene en una necesaria transformación de la conciencia para integrarnos a la unidad de la vida, cuya lógica es la dialógica comprensiva". (p.44). En este sentido la transmodernidad en plena consideración respalda el carácter ecosófico de la investigación. Pupo (2014) habla del carácter ecosófico en la reflexión sobre nuestras costumbres, el cuidado de la tierra como el patrimonio natural más grande, también la relación ciencias y los saberes provenientes de la cultura.

Desde luego para la realización de la indagación hermenéutica comprensiva, diatopica y ecosófica se recorren los niveles que están profundamente relacionados estos son: los planteados por Santos (2003) analítico, empírico y propositivo; o, los de Ricoeur (1965), semántico, reflexivo y ontológico. Los niveles analítico y empírico o equivalentemente los semántico y reflexivo cumplen desde el presente Rizoma hasta el Rizoma siguiente. Y el nivel propositico u ontológico donde visionan salidas a la problemática se da en los dos últimos Rizoma de la indagación.

En el presente rizoma también se introducen en categorías constitutivas de la indagación como rizoma, cultura, patrimonio cultural, transcomplejidad, Educación Patrimonial, formación docente, ecosofia y transmodernidad. La palabra rizoma que usa de manera envolvente en los subtítulos de la presente investigación tiene una insinuación circundante, atiende a Deleuze y Guattari (1980) en el que de manera compleja puede ser conectada con cualquier otro los razonamientos y ramas que constituyen la disposición; es una anti-genealogía que rompe con las estructuras estáticas divisorias de presentar las investigaciones en las que las partes dividen indisolublemente en un ir si un venir. Acá la organización no responde a ningún modelo estructural o generativo. 


\section{La Educación Patrimonial y la Formación Docente desde la Transcomplejidad}

Por otro lado, para Rodríguez (2017) la cultura es una abstracción, un constructo teórico que delimita el comportamiento de un conjunto de seres humanos; el conocimiento adquirido que las personas utilizan para interpretar su experiencia y generar actuaciones; realidades profundamente cambiantes; para nada acabadas y que configuran con la identidad de los sujetos históricos. Entonces, es la cultura la trama de significados con la que los seres humanos interpretan su existencia y experiencia, conducen sus acciones.

Un todo complejo la categoría cultura; conjunción de saberes, creencias, arte, moral, derecho y las costumbres y adquiridas del individuo en sociedad; pero que subjetivan en la realidad del momento; de esos saberes dan cuenta tanto los científicos, como los soterrados olvidados al no pasar por el filo de las ciencias. El patrimonio cultural, Moreno (2007), tiene visiones inacabadas que permitan un empoderamiento y reconocimiento de la particularidad y de la apropiación plena, subjetiva y emancipadora de la cultura, pero no aquella entendida escuetamente; sino la complejizada como sistema de valores, creencias, tradiciones, costumbres y horizontes utópicos.

Mosonyi (2012) también habla del patrimonio cultural en el sentido de "desmontar el discurso eurocentrista que ha permanecido sobre estos pueblos, llamar la atención sobre valores y aportes a nuestra sociedad en contra de la ignorancia que tiene en cuanto a su cultura, modos de vida y vestimenta" (p.24). Un reconocimiento de la cultura, la interculturalidad, el patrimonio cultural en toda su complejidad da cuenta entonces de la valoración del ser humano y su posición ante el mundo en épocas de profundos cambios.

Esta manera de pensar y de constituir una investigación sólo es posible en la transcomplejidad donde la complejidad y transdisciplinariedad constituyen el transparadigma. González (2014) afirma que "este pensamiento transcomplejo ha construido conceptos científicos educativos muy importantes como aula mente social, emergentes educativos, metacomplejidad, deconstrucción educativa y complejidades curriculares". (p.13). El hecho de mirar desde su complejidad, descolonización y ecología de los saberes a la Educación Patrimonial es de un especial valor e interés en la vida y rescate de la verdadera identidad descolonizada de los ciudadanos de Venezuela; pues el vivir desde la consciencia y el orgullo de lo que somos cobra preeminencia en el rescate de nuestra cultura en un proceso de globalización en todos los niveles. Seguimos siendo colonias reducidas a artefactos de saqueo cuando las mentes siguen colonizadas.

Esta posibilidad de mentes descolonizadas es posible en la transmodernidad, no son pocas las razones sustentadas en Enrique Dussel de como en la transmodernidad encuentra el asidero necesario para la realización de dicha 
investigación; sigue afirmando Dussel (1992) “este proyecto transmoderno será también fruto de un diálogo entre culturas". (p.162). Es aquí donde tiene sentido la diversidad cultural en pleno; sin soslayarla; sin incisiones; pero cobrando preeminencia por lo nuestro autóctono.

Más aún, el transparadigma transcomplejo como piso en la Investigación es el camino viable para desentrañar la madeja tejida que sostiene el desequilibrio social e impide una evolución más expedita del asunto patrimonial ante la ciudadana y en la conformación de una verdadera identidad que este fuera de las mentes colonizadas, en la descolonización en Venezuela. El transparadigma transcomplejo dibuja la posibilidad del decaimiento de los dogmas epistemológicos y metodológicos y da opción a una mirada de saberes patrimoniales interconectados con todas las áreas del saber y con la Educación Patrimonial en donde de acuerdo con Ruiz (2008) "se supera el reduccionismo que es más un modismo intelectual que una perspectiva ontoepistemológica”. (p.16).

En la modernidad la ecosofía tiene su realización plena; Guattari (1996) es la ciencia del siglo XXI, "su objeto, la sabiduría para habitar el planeta. Propone pasar a la mundialización, rescatar lo local, revisar la visión que tenemos del mundo (...) la clave, saber en qué forma vamos a vivir de aquí en adelante sobre este planeta" (p.59). La sabiduría para habitar el planeta como ciudadanos éticamente responsables pasa por la condición humana que reconoce la necesidad del conocimiento y cuidado de su patrimonio cultural y natural.

Desde luego la Educación Patrimonial Transcompleja que irá delineando con sus visiones o ejes teóricos tiene un escenario denominado aula mente social, González (2015) afirma que "un aula compleja social que tome en consideración la práctica transdisciplinar, la inmersión hacia los saberes científicos y tradicionales en correspondencia al conocimiento científico y tecnológico. (...) El aula deja de ser aula y la clase se convierte en un aula mente social compleja y transdisciplinar. (p.5).

Por otro lado, la formación docente tradicional acá será reconstruida para envolverse de la transcomplejidad en el proyecto transmodernista, luego que en la sesión siguiente se hable de su tradicionalidad y se describan sus principales males. Urge formar así al docente, no sólo para el saber eficaz sino en la inteligencia integral: analítica, sistémica, sensible, corporal y profundamente humana. Es por ello que Pérez (2003) afirma que "la complejidad hace de la enseñanza un proceso de constante inclusividad, basado en la investigación desde la interdisciplinariedad" (p.196). Y la cultura debe ser una vía para la transformación de la formación docente enmarcada en la liberación etnocéntrica de la transmodernidad. 
En lo que sigue la hermenéutica comprensiva, diatopica y ecosófica sigue cobrando sentido; para ello las categorías expuestas amalgaman como un todo para presentar la Educación Patrimonial y formación docente tradicional.

\section{Rizoma crisis: La Educación Patrimonial y formación docente tradicional}

En el comienzo de la indagación se afirmó que la Educación Patrimonial en Venezuela está en crisis y ella hereda de la educación general todo el reduccionismo y colonización del saber y poder que en adelante explicita tocando aristas como los ejes de poder, las normativas y otros hechos.

En particular, las normativas aplicadas por el ejecutivo a nuestro patrimonio cultural intangible indígena, en particular, en el período posterior a la declaración de independencia de Venezuela, son cuestionadas por Uzcátegui (2007) quien plantea cualquiera pensaría que "una vez llegada la independencia de Venezuela, la situación de los indígenas cambiaría, pero la realidad fue otra; ahora los criollos eran los verdugos de los indígenas, promulgando leyes que estaban en contra de las costumbres de los aborígenes" (p.12).

En el siglo XX, profundizó la reducción, hispanización y civilización de los indígenas, en 1915, con la Ley de Misiones contempla en el Artículo 1 "reducir y atraer a la vida ciudadana las tribus y parcialidades indígenas no civilizados que aún existen en diferentes regiones de la República" y en el Artículo 2 la enseñanza con personal misionero que debía conocer el idioma castellano y un oficio, por lo menos para enseñarlo".

Desde el período democrático, la educación vinculada a la ciudadanía, identidad y patrimonio cultural han tocado en la educación formal a través de asignaturas como Formación Cívica y Ciudadana, permeando la identidad y ciudadanía, afectando el patrimonio cultural de los indígenas y afro descendientes sin considerar su complejidad; lo hacen en forma fragmentada, tales afirmaciones las avala Villalón (1994), al señalar que ha sido un proceso asimilacionista, hispanizante que trastoca la identidad y ciudadanía venezolana. Actualmente, en la enseñanza patrimonial, de ciudadanía e identidad abordan a través del Sistema Educativo Bolivariano, que plantea algunos indicios de transdisciplinariedad que no llegan a concretarse, a través de las áreas de aprendizaje: Lenguaje, Comunicación y Cultura y Ciencias Sociales, Ciudadanía e Identidad; trayendo como consecuencia una disyunción con el concepto de patrimonio cultural y de la Educación Patrimonial.

Más aún, en la actualidad con la Misión Robinson en los pueblos indígenas hay serias críticas que avala Mosonyi (2009) cuando dice "nadie duda que las Misiones Robinson han enseñado a muchos indígenas a leer y escribir; pero en la mayoría de los casos ignoraron las lenguas nativas y las culturas correspondientes" 
(p.169). Es como desde dichas misiones hay una falta de reconocimiento de la cultura de los aborígenes que desde luego incide en la conformación de su identidad y de su responsabilidad como ciudadano ante la defensa de su patrimonio.

Sigue afirmando Mosonyi (2009) "en la práctica, pero también un poco en teoría, estas Misiones continúan siendo unidireccionales, vale decir, aportaciones de la sociedad dominante y occidentalizada dentro de una tónica que años atrás calificábamos de "neopaternalista". (p.169). Sigue promoviendo desde nuestras políticas culturales en la práctica visiones reduccionistas, transculturizadas y colonizadas de nuestra cultura y de allí la conformación de un ciudadano ajeno a su cultura con una identidad que no es la de sus orígenes. Aunado a esta realidad la Educación Intercultural Bilingüe y tal Diseño Curricular coexisten en una imposición cultural a través de la educación que incide en la ciudadanía; tal situación la sustenta Mosonyi (2009). Trata de que desde el paradigma modernista se ha formado un ciudadano y legitimado aquel sumiso ateniente al sistema e intereses particulares, defensor del capitalismo como expresión de democracia, son muchas veces los ciudadanos intelectuales orgánicos sometidos. Estas realidades las explicita Rodríguez (2017).

De todas estas realidades ha estado permeada la Educación Patrimonial del país. Al respecto Villalón (2011) plantea el incremento de la castellanización y el empobrecimiento de la diversidad lingüística venezolana, al respecto expresa "el hecho que las lenguas continúen mermando a pesar de un envidiable marco jurídico que persigue todo lo contrario" (p.147). Es nuestra cultura autóctona en franca decadencia ante normativas que van por un lado y la realidad por otra, el proceso decadente de la Educación Patrimonial y el patrimonio cultural, la cultura, la identidad cultural sigue presente.

El 20 de Diciembre de 2011 en nuestro país entró en vigencia la Ley Orgánica de la República Bolivariana de Venezuela (2009) contra la Discriminación Racial, la cual establece en su Artículo 19 que: "en todos los niveles y modalidades del Sistema Educativo incluirán contenidos relativos a las culturas, historias y tradiciones constitutivas de la venezolanidad, destinados a prevenir, eliminar y erradicar toda forma de discriminación racial". Además en la Ley Orgánica de Educación de la República Bolivariana de Venezuela (2009) en su Artículo 4 en cuanto a educación y cultura expresa que "la educación como derecho humano y deber social fundamental orientada al desarrollo del potencial creativo (...) El Estado asume la educación como proceso esencial para promover, fortalecer y difundir los valores culturales de la venezolanidad". 


\section{La Educación Patrimonial y la Formación Docente desde la Transcomplejidad}

Pese a todos estos marcos jurídicos la Educación Patrimonial desde la educación formal y también de la no formal de nuestro país no aborda la problemática del patrimonio cultural y sus concepciones los saberes patrimoniales desde la complejidad. La diversidad cultural es atendida primariamente desde la Educación Intercultural en las escuelas de zonas indígenas y la Ley Orgánica de Educación de la República Bolivariana de Venezuela (2009) en su Artículo 27 expresa "la educación intercultural transversaliza al Sistema Educativo y crea condiciones para su libre acceso a través de programas basados en los principios y fundamentos de las culturas originarias de los pueblos y de comunidades indígenas y afrodescendientes, valorando su idioma, cosmovisión, valores, saberes, conocimientos y mitologías entre otros, también su organización social, económica, política y jurídica, todo lo cual constituye patrimonio de la Nación. El acervo autóctono es complementado sistemáticamente con los aportes culturales, científicos, tecnológicos y humanísticos de la Nación venezolana y el patrimonio cultural de la humanidad". Existe el reconocimiento de obras de patrimonios culturales materiales e inmaterial como es el caso, en Venezuela de la UCV nuestra Universidad Central de Venezuela; Los Diablos Danzantes, El sistema Normativo de los Wayuu, entre otros. Pero están muy distante las aseveraciones de este artículo legal de la realidad en los escenarios venezolanos; tal situación la ratifica Guerra y Rodríguez (2017).

Para terminar esta sección de la problemática generalizada de investigación, la autora afirma que está en la búsqueda de miradas otras, aquellas no reduccionistas, del patrimonio cultural desde visiones inacabadas que permitan un empoderamiento y reconocimiento de la particularidad y de la apropiación plena, subjetiva y emancipadora de la cultura autóctona, pero no aquella entendida escuetamente; sino la complejizada como sistema de valores, creencias, tradiciones, costumbres y horizontes utópicos; Moreno (2007). Hacia estos caminos descolonizantes nos conduce la transcomplejidad; piso epistémico que se explicó debidamente en las bases teóricas de la indagación en el presente Rizoma.

Por otro lado, la formación docente tradicional ha venido colaborando en una educación enmarcada en el proyecto modernista. En la maravillosa relación formación-cultura, Accorinti (2000, p.6) plantea que la bildung relaciona estos dos términos, "pero solo en tanto patrimonio personal del humano culto, en su sentido individual y no en el sentido de apropiaciones culturales que pudieran tener los grupos humanos, pero no el individuo". Ha legitimado, por ejemplo, el maltrato a la mujer en cuanto a su sumisión ante el más fuerte físicamente o prejuicios como que las mujeres no sirven para estudiar matemáticas. Tales y tantas situaciones que minimizan a los seres humanos y que los dividen entre los capaces e incapaces, los alienan a su conveniencia y desvalorizan con ello a nuestros aborígenes, y con ello nuestro 
patrimonio cultural, convirtiéndola en la "educación bancaria" de la que el gran pedagogo Freire (2002) da cuenta.

Afirma Rodríguez (2017) refiriéndose a la situación narrada anteriormente que en el ámbito de la educación y la cultura también ha denigrado a las personas por su color, religión y política; ha proliferado el dominio del mundo por unos pocos que tienen el poder económico y que deciden por una mayoría, víctima de las injusticias y la dominación por el enfoque de la educación como proyecto hegemónico.

La formación docente ha sido tan soslayadora aún con serios rezagos actualmente de ello que la actualidad que el individuo ha sido objetivado en un proceso finito, concluido; resultado de una educación positivista, reduccionista, economicista que ha entendido como el vehículo instrumental para alcanzar metas económicas compatibles con sus aspiraciones e intereses. Sin embargo, para Edgar Morín es necesario enfrentar la fragmentación, desenterrar al máximo la teoría de los sistemas en una visión que aspire a conocer lo más posible al ser humano.

\section{Rizoma propositivo: La Educación Patrimonial Transcompleja y la formación docente transcompleja}

La EPT se construyó también con las ideas especial de González (2010; p.116) quien afirma que "la educación transcompleja permite justamente la reflexión humana como centro de comprensión en el accionar humano". (p. 116). No es una educación reproductiva o materialista sino una educación social donde los seres humanos contrarios armonizan y los semejantes se complementan.

En la Educación Patrimonial en general parte de la premisa de Morín (1998) que afirma es urgente derribar las murallas del conocimiento fragmentado entre las disciplinas y así buscar la manera de volver a unirlo mediante diadas y hacer visibles las conexiones existentes; es más reinventarse las que no son tan evidentes; en este caso quiere ver el conocimiento de los saberes patrimoniales inmiscuidos y transversalizador por los demás saberes, es la complejidad de los conocimientos en general; romper las incisiones unidisciplinares, las fronteras del conocimiento que tanto daño han hecho; de la misma manera las barreras entre los saberes científicos y los soterrados. Es urgente Moreno (2016) "generar una educación patrimonial basado en el pensamiento complejo, atendiendo a la necesidad de considerar a los patrimonios como un concepto complejo" (p.65).

Es urgente de acuerdo con las premisas de la complejidad diseñar estrategia que permitan enfrentar los riesgos, lo inesperado, lo incierto, y atender el proceso educativo como aquel lleno de profundas incertidumbres y no de determinismos. También parte de la acepción de antecedentes a esta investigación donde clama por 


\section{La Educación Patrimonial y la Formación Docente desde la Transcomplejidad}

evitar que el patrimonio cultural muera en la vida social de los ciudadanos, como la define García (2016) "la educación patrimonial es una vía para construir redes cognitivas y afectivas con el patrimonio y promover la participación de las comunidades locales en la valoración de su patrimonio material e inmaterial" (p.41); pero con el transparadigma transcomplejo con piso epistemológico.

En la concepción de la EPT se van tejiendo pisos epistemológicos que no están separados de lo que denomina educación formal, que es la que se da en las instituciones educativas y las no formales que no pertenecen a ella, tal separación no existe. Sin embargo, se quiere acá en este espacio la EPT pensar en la educación formal en tanto constituye la formación docente en cualquier nivel educativo pensando en los saberes patrimoniales. Intenta conformar un aula compleja social, que conciba la EPT como aquella profundamente transdisciplinar, no separada de la enseñanza de las ciencias. El principio máximo en la educación de la complejidad es la no separación del conocimiento, ejemplarizaciones de la transcomplejidad.

Lo transdisciplinar del conocimiento en general y en comunicación con los de los saberes patrimoniales conduce a su interrelación, a su dialogo directo o indirecto con otras disciplinas, dialogo ubicado en los planos horizontales y verticales que permita la flexibilidad, transformaciones, tolerancia a la incertidumbre de la misma manera que la aceptación a la diversidad cultural, a su ordenamiento curricular, intercambios que permitan el acercamiento a la realidad de las problemáticas que dan con la cultura y sus diversos cambios en la vida de los ciudadanos participes del proceso educativo en el aula mente social. Estas ideas integradoras del conocimiento mediante la dialéctica, el dialogo las respalda Balza (2013) cuando afirma que lo importante de lo epistemológico del "enfoque integrador transcomplejo, es que entre la intención de la mediación del conocimiento y la pretensión de reconocimiento del mismo, germine una argumentación sustantiva que nos ayude a disipar las dudas que nos asaltan frente a la emergencia de una nueva verdad" (p.2).

En las instituciones educativas venezolanas con todas sus particularidades la EPT en la formación de los docentes es clave, es ante todo un proceso de vida en la formación de un ciudadano transmoderno; trata de desarrollar una forma de pensar capaz de comprender la existencia de la vida en el planeta recapacitando en una cultura, dejando el paradigma simplista - reduccionista e ir más allá de la posición antropocéntrica del ser humano y reconocer las inter-retro-acciones de los sistemas del planeta y trascender a un nuevo nivel de razonamiento que conlleva, indefectiblemente al pensamiento complejo y a la actitud transdisciplinar.

Deja de ser un docente individuo individualista, en cuanto a su formación indisciplinar y comienza reconociendo su responsabilidad en el mundo; en la diversidad cultural en que está inmerso; es ante todo un ciudadano explorador y 
empoderado de su cultura; y entiende que esta es vital para la humanización. Freire (1975) muy sabiamente lo expresa que "como seres de praxis, transformar al mundo es humanizarlo, incluso si el hecho de hacer que el mundo sea más humano no signifique la humanización de los hombres" (p.60).

Como ciudadano envuelto en una concepción descolonizada el docente es un ser humano que ha sido rescatado de las imposiciones unidireccionales y proyectos hegemónicos soslayadores de nuestra cultura; Rodríguez (2012) afirma que en "la transmodernidad se rescata ese ser autónomo de cada uno, se reafirma la búsqueda de puntos referenciales para el comportamiento social en un contexto histórico fundamentado en valores esenciales y un proceder ético" (p.172).

Es esta la mirada inicial de cualquier ciudadano docente, de la que como practicante y defensor de nuestra cultura y en plena conciencia de la transdisciplinariedad del conocimiento busca miradas otras para la promoción de la cultura, su diversidad, su patrimonio cultural y natural. El docente es entonces un ciudadano que sabe que la EPT es una práctica concientizadora de los seres humanos con el conocimiento y la conjunción de los saberes científicos y soterrados en pleno ejercicio, de acuerdo con Morín (1998) de la reforma de su pensamiento que permitiría que con el desarrollo de su antropoética en conexión con sus inteligencias quiera dar líneas de salidas a los grandes desafíos del país, de la sociedad en pleno; es un ciudadano con el mundo y en el mundo, tal cual Paulo Freire cada día más vigente, es la educación en la ciudad; trata de una formación tendente a la necesaria transformación educativa.

Es de hacer énfasis que la EPT debe estar concebida bajo la reforma del pensamiento de sus actores; lo expresa muy puntualmente González (1997) "sólo por medio de una depuración del pensamiento podremos buscar nuestra herencia cultural hispano-lusitana y afroamericana, pero por sobre todas las cosas, en la original y multiforme cultural popular latinoamericana, (...) de ofrecerlo al planeta como nuestra" (p.30).

Entonces se puede afirmar que la EPT como practica concientizadora de la cultura, del patrimonio cultural, de los saberes patrimoniales en general es aquella que impulsa al individuo hacia un proceso reflexivo de carácter permanente sobre su realidad cultural que desde luego también es social y política; docente que primero encontrándose sí mismo con sus raíces pueda guiar a los demás a por ese camino, reconocerse en sus semejantes, tomar conciencia del entorno que lo, y que muchas veces lo ha soslayado y confundido en su identidad; propiciar acciones para transformarlo además de liberarse de la obstáculos que limitan el desarrollo de sus 


\section{La Educación Patrimonial y la Formación Docente desde la Transcomplejidad}

potencialidades y orientarse a la adquisición de una nueva manera de pensar sobre su ser y estar en el mundo. De estas ideas de concientización deja cuenta Freire (1997).

La novedad en la EPT, para el docente es la transcomplejidad y esta no es la solución a la crisis en su formación, es un camino que en el andar le abre brechas y escenarios que con la cultura aborda hechos de completa transcendencia. Para el docente convierte el ser conocedor de la cultura y de los saberes patrimoniales le permite la resemantización de la relación de su disciplina con el atravesar en una aventura de su pensamiento los saberes, ya no considerados estos aislados; sino enriquecidos con armonías de conexiones inimaginables, abiertas a otras posibilidades de existencia y concepciones. Esa es la razón por cual no se persigue, como lo hacía el docente tradicionalista, el planteamiento de métodos, programas o propuestas metodológicas a modo de soluciones rápidas perfeccionistas y únicas, por el contrario, es muy novedoso pensar en aprender; por ejemplo, estudiar las figuras geométricas ayudaría a conocer la historia de las obras patrimoniales y la indagación de su significancia en la vida de sus discentes; y no sólo el conocer la obra como imposición cultural. García (2012) señala que "fomentar la formación profesional de docentes de aulas y de museos en EP en Venezuela" (p.215).

Aspira entonces con la transcomplejidad un docente abierto a nuevas estructuras mentales y aventuras investigativas, con diversas miradas, fuera de las acomodadizas que imponía en el pasado. Balza (2017) en el "caso del profesor universitario, su formación integral debe nutrirse de la riqueza de los contenidos de todas esas representaciones ideoculturales para favorecer la construcción de identidades colectivas desde su praxis pedagógica, andragógica y/o heutagógica para la educabilidad del ser humano" (p.32).

Entra acá en juego, la subjetividad del docente que concierne a aspectos educativos de carácter como el conocer con lo epistemológico, el buscar las causas, finalidades y propósito del ser humano en la tierra con lo teleológico, aquí comprende desde su cultura y patrimonio cultural porque es lo que es y no de otra manera y desde luego renueva sus valores a las nuevas necesidades un individuo antropoético con lo axiológico. Todas estas perspectivas respaldan a la concepción del docente como sujeto ciudadano del mundo y abogan por el desarrollo de un pensamiento crítico, reflexivo, flexible, dialógico, autónomo del docente, el fomento de la intuición y el rescate de la subjetividad durante su actuación profesional que no la separa de su vida cotidiana, su investigación y prácticas culturales.

Todas estas perspectivas llevan a comprender al docente la necesidad de grupos de trabajos de investigación y planificación que permitan permear de ideas las distintas concepciones de cada conocimiento, su comunicación e interacción en marco de un trabajo colaborativo; este es una clave en la EPT; trata de lograr consensos en la 
divergencia, aceptar la incertidumbre, lo indecible, atravesar enfoques integradores transcomplejos.

En esta convergencia de grupos de docentes investigadores genera una sinergia de aceptación de que la cultura no es estática que no existen conocimientos culturales; sino saberes culturales, patrimoniales que legitiman en la medida que las indagaciones y aceptación de la comunicación entre los saberes se da. Es un cambio y reforma del pensamiento de los docentes que no es fácil de lograr; pero que en los rizomas de la complejidad es posible.

En estos grupos colaborativos de docentes investigadores aplica el principio organizativo de la complejidad, de la que Morín (1998) afirma son "principios organizadores que permitan vincular los saberes y darles sentido". (p.23). En este caso en vez de estar separando los saberes de las distintas ciencias existe la armonía entre ellos y son atravesados con la transdisciplinariedad que generan nuevas interrelaciones. En este sentido pueden producirse en la EPT bucles recursivos por ejemplo cerebro-mente-cultura, de acuerdo con Morín (1998) y aquí aparece la unidualidad del ser humano, en tanto él no es sólo un ser biológico como ha venido creyendo; sino que también es un ser cultural. De esta manera todo conocimiento, en especial el cultural es, de acuerdo con Morín (2002) "una reconstrucción/traducción que hace una mente/cerebro en una cultura y un tiempo determinadas" (p.101).

En tales consideraciones de la transdisciplinariedad, y siguiendo a Nicolescu (1996) cuando habla de las tres rupturas primordiales que conlleva la transdisciplinariedad el docente con la EPT lleva a romper con la creencia que la totalidad de la cultura limita a la realidad que vemos y percibimos y comprende que es mucho la que está por descubrir, por reconstruir por valorizar, por ejemplo los patrimonios culturales no valorados, más aún la valorización de los que tenemos, el docente rompe con el lenguaje repetitivo y excesiva cientificidad que nos inscribe en su limitada perspectiva de la cultura y abre a la diversidad cultural a las culturas olvidadas y desgarra el caparazón instalado en sus vidas transculturizada y por último romper con un modo de vida esclerotizado y convencional donde cree que adaptarse a culturas o estereotipos de estas, en apariencia más avanzadas, que no son nuestras lo hace mejor persona.

En este caso, es importante mencionar el papel de las Universidades en estas rupturas, Nicolescu (1996) afirma que en estas "podrá devenir un lugar de aprendizaje de la actitud transcultural, transreligiosa, transpolítica y transnacional, del diálogo entre el arte y la ciencia, eje de la reunificación entre la cultura científica y la cultura artística" (p.7). Es la conjunción de los ejes epistemológicos de los saberes populares y científicos en estas instituciones que devienen de la transdisciplinariedad como eje 


\section{La Educación Patrimonial y la Formación Docente desde la Transcomplejidad}

integrador y unificador de dichos conocimientos que devienen al hecho cultural donde se asuma, García (2014) "el patrimonio cultural como un espacio de complicidades sociales para definir el entorno y establecer formas de autorepresentación de la sociedad" (p.6), desde luego y de acuerdo con la autora citada la Educación Patrimonial se conforma desde esta mirada como una praxis educativa y social consiente construir gestiones pedagógicas privilegiando enfoques interdisciplinarios, dando cabida entonces a la EPT.

Encaja muy bien acá y es comprensible la aseveración de Nicolescu (1996) cuando afirma que un ser humano en consideración con la transdisciplinariedad y la conformación de sus saberes pasa por una conversión del alma, lo que se ha venido perfilando, la antropoética, y con esta los valores de aceptación, respeto, tolerancia hacia el reconocimiento de las diferencias con la cultura de cada grupo. Esta actitud del docente en el país y en el continente en momento de confrontaciones y cambios es deseada, y no sólo ella conlleva el imperativo de salvación del planeta y las especies en extinción. Contiene esta actitud transdisciplinar del docente la tolerancia, la apertura a otras culturas y desde luego argumentaciones científicas más ricas justificadas por la gran interacción con los saberes manifiestan en la apertura deseada.

En esta conformación de la EPT es importante mencionar como sería el camino para un currículo le dé cabida a ésta, González (2012) lo dice claramente "el currículo por lo tanto tendrá un alto sentido de inacabado, inmerso en un entretejido educativo emergente" (p.18), trata de un currículo que incite a religar con todo un entramado de posibilidades complejas y transdisciplinares para facilitar una itinerario emergente con un objetivo es el de formar ciudadanos capaces de afrontar los cambios y reconstrucciones de la cultura en la constitución de su patrimonio cultural. Este currículo transdisciplinario lleva, según Barreto (2010) a "la necesidad de reforzar la cuestión ética (...), de atender al problema del desarrollo humano integral y de formar personas comprometidas con su entorno" (p.8); desde luego con las necesidades de la conformación de su identidad cultural.

Tomando en cuenta que los ciudadanos se forman en un aula mente social la formación del docente debe estar pensada en un dialogo externo e interno, tiene íntima relación con los procesos de incertidumbre de la no certeza y determinación de la cultura, González (2012) denomina este proceso conformativo un diseño curricular por complejidades, salta la razón de las competencias; entendiéndose que cualquier ciudadano ira conformando una identidad solida pensando en su cultura sin pensar está apto para saber o aprender de ella; pues ella ya lo determina como tal.

Trata de un docente poseedor del pensamiento transcomplejo, a los que Balza (2013) afirma encarna una cosmovisión emergente "acerca del mundo (...) pues es la manera de crear puentes transdialógicos y multicomunicantes entre lo simple y lo 
complejo, entre lo natural y lo humano, lo configuracional y transconfiguracional, siempre desde el dialogo concurrente de las distintas disciplinas del conocimiento" (p.187). Es de hacer notar esta cosmovisión es profunda desde la economía, política, ambiente, ecología, religión cultural, espiritual y cerebro. Pero también encarnado en los saberes populares, en la cultura popular y autóctona. Es una cosmovisión transcomplejizada por la diversidad cultura y la aceptación de las diversas formas de manifestar nuestra cultura, mucha de ella se ha negado a morir en los procesos negadores de ella, de los que se ha explicado en exuberancia.

Es de hacer notar según González (2008) este diseño mencionado lleva elementos de auto-organización, orden-desorden e incertidumbre, autorreflexión, estrategia compleja, trabajo en equipo (grupos transdisciplinares) y una formación basada en la investigación compleja. Es así como caduca el docente solitario, encerrada en su disciplina no intercambia con grupos o comunidades de aprendizaje y deja fuera los elementos culturales como actividades recreativas o extraacadémicas o de fiestas especiales.

En el caso de las universidades, es especial para los formadores Balza (2017) "el docente universitario del siglo XXI, debe nutrirse de bases conceptuales emergentes, de sólidos fundamentos filosóficos, sociológicos, psicológicos y pedagógicos surgidos de la investigación, para poder estar acorde de la emergencia de nuevos paradigmas educativos" (p. 29).

Todas estas bases conceptuales pueden estar cargadas de elementos culturales propios de la vida de los actores del proceso educativo. En especial recogiendo todas las aseveraciones deseables del docente González (2010) asume que es necesario articular un currículo transcomplejo en la formación docente; como se recoge de lo dicho acá que parte de la complejidad vinculando los conocimientos con la transdisciplinariedad. Rompe entonces el esquema unidisciplinario y emergen categorías constitutivas alrededor de la cultura y patrimonio cultural en todas las ciencias como lo expresa el mismo autor; lo contenidos curriculares complejizan, religan y emergen en un currículo abierto, flexible, dialógico y recursivo. De todo ello con la investigación transcompleja podemos realizar imaginarios transversales con la cultura en todos campos cotidianos del hacer del ser humano; de la ciudad, de la calle, del hábitat popular.

\section{Rizoma Final: Devenir de la Educación patrimonial y la formación docente desde la transcomplejidad}

La EPT es el ejercicio educativo que tiene por base el asunto patrimonial esencialmente política y se muestra como un dinámico elemento de ciudadanía e 


\section{La Educación Patrimonial y la Formación Docente desde la Transcomplejidad}

inclusión social de la cultura autóctona. Donde los espacios de independencia y autodeterminación venezolano están en consonancia con su cultura; ejercicio educativo es atravesado pon la cotidianidad y los saberes soterrados; la historicidad en la EPT forma parte de la vida del ciudadano y la conformación de su identidad; hacia la defensa del patrimonio más universal: la tierra. De acá que la ecosofia es altamente relevante en el individuo, ciudadano antro - poético pues esta empoderado de la sabiduría para habitar su país.

Dicha educación configura como una praxis educativa y social que permite elaborar acciones pedagógicas, privilegiando enfoques transcomplejos, transversales y complejos percibiendo su dimensión histórica, fortaleciendo su compromiso como ciudadano en la ciudad; su identidad y subjetividad cobran un papel fundamental los saberes científicos y soterrados en igual grado de importancia, en plena transdisciplinariedad. Es menester la particularidad del currículo transcomplejo contentivo de la intencionalidad de una EPT donde el currículo regional este adaptado a la lengua y necesidades particulares. De esta manera la EIB y la EI tienen influencias y es influenciado por la EPT; para ello los formadores pioneros de la EPT debe formar grupos transdisciplinares atiendan por ejemplo a la Educación Patrimonial Indígena y a la salvaguarda del patrimonio cultural intangible en los aborígenes; su vida en la comunidad y condiciones de su hábitat.

Sin duda el papel de las políticas educativas es urgente en la conformación de la EPT; es importante la formación docente con grupos transdisciplinares, enmarcado en la transmodernidad; en un proceso descolonizado de valoración y respeto por nuestra cultura; la conformación y dotación de materiales, aulas y el reconocimiento de la diversidad cultural como el único patrimonio cultural universal. En este caso el papel de las instituciones educativas es esencial.

La EPT configura como un proceso dinámico, emergente, religante y relativo donde se complejiza el patrimonio cultural desde aprender, desaprender y reaprender siguiendo las huellas de los saberes patrimoniales. Como el contexto de los discursos y las prácticas en el día a día de la EPT se realizan con las mentes descolonizadas de los docentes, del ciudadano. El desarrollo de la nación va en consonancia con la EPT y sus políticas educativas patrimoniales. Por ello la EPT como alfabetizadora del ciudadano tiene mucho sentido. Cuentan muchos profesionales analfabetos culturalmente; practicantes transculturizados que desvalorizan nuestra cultura.

\section{Referencias bibliográficas}

Accorinti, Stella. (2000). Máscaras para el laberinto de la bildung. Cómo se llega a ser lo que Ariadna es. Conferencia pronunciada en las Jornadas Nietzsche 2000, Nietzsche (no) ha muerto: entre arte, filosofía y política. Universidad de Buenos Aires: Argentina. 
Balza, Antonio. (2013). Pensar la Investigación Postdoctoral Desde Una Perspectiva Transcompleja. Editorial REDIT. Venezuela.

Balza, Antonio. (2016). Filosofía e investigación educativa desde la transcomplejidad. En libro: Investigación transcompleja. Génesis, avances $y$ prospectivas. Red de Investigadores de la transcomplejidad REDIT, Universidad Bicentenaria de Aragua: Venezuela.

Balza, Antonio. (2017). Formación docente, conocimiento y tecnología. Argumentos desde la transcomplejidad. En libro: $T^{2}$ : $T I C^{\prime} s \quad y$ Transcomplejidad. Otros Ángulos de la realidad. REDIT, Universidad Bicentenaria de Aragua: Venezuela.

Barreto, Nancy. (2010). Tendencias curriculares a considerar en los procesos de cambio educacional. Revista Nuevas Tecnologías y Sociedad. 61. España. (Pp. 23-45).

Deleuze, Gilles y Guattari, Félix. (1980). Rizoma (Mil Mesetas 1980). Minuit. Francia.

Dussel, Enrique. (1992). La ética de la liberación: ante el desafío de Opel, Taylor y Vatio con respuesta crítica inédita de K.-O. Opel. Universidad Autónoma del Estado de México. México.

Freire, Paulo. (1975). Acción cultural para la libertad. Tierra Nueva. Argentina. Freire, Paulo. (1997). La educación en la Ciudad. Siglo XXI Editores. México Freire, Paulo. (2002). Pedagogía del oprimido. Siglo XXI. México.

García, Zaida. (2012). La Educación Patrimonial en Venezuela desde una Visión Latinoamericana, Una propuesta de modelo teórico. Trabajo de Grado. Doctora en Educación. Universidad de Sevilla. España.

García, Zaida. (2014). Maestros que conectan saberes a través del patrimonio cultural.

CLIO. History and History teaching. 40. España. (Pp. 1-12).

García, Zaida. (2016). ¿Cómo impedir la muerte social del patrimonio cultural? Educación Patrimonial un área emergente. MOUSEION, 23. España (Pp. 41-56).

González, José. (2008). Reflexiones iniciales sobre la concepción del diseño y desarrollo curricular en un mundo contemporáneo y complejo. Revista Integra Educativa, 1 (2). Bolivia. (Pp. 13-58).

González, Juan. (2010). Teoría Educativa Trans-compleja. Edición La Paz: IIICAB. Bolivia.

González, Juan. (2012). Teoría Educativa Transcompleja. Tomo I. Universidad Simón Bolívar. Colombia.

González, Juan. (2014). Paradigma Educativo Transcomplejo Educación del siglo XXI. Revista Ciencias Farmacia y Bioquímica. Volumen 2. Número 1 Bolivia. (Pp.11-16).

González, Juan. (2015). Tiempo-espacio en el Aula Mente Social. Revista CONCIENCIA, 3(1). Ecuador. (Pp. 9-16). 
González, Sergio. (1997) América Latina y la complejidad. En Sergio González (Comp.) Pensamiento complejo. En torno a Edgar Morín, América Latina y los procesos educativos. (23-22) Cooperativa Editorial Magisterio. Colombia. Guattari, Félix. (1996). Las tres ecologías. Pre-Textos. España.

Guerra, Saida y Rodríguez, Milagros. (2017). Formación de investigadores educativos interculturales en los pueblos indígenas: visiones en Venezuela. Capítulo en: Formación de Investigadores Educativos en Latinoamérica: Hacia la construcción de un estado del arte. Red Durango de Investigadores Educativos, A. C. Chiapas, México.

Moreno, Ignacio. (2007). Complejidad y Educación Patrimonial. Universidad de la Ciénaga del Estado de Michoacán de Ocampo. Instituto Michoacano de las Ciencias de la Educación. México.

Moreno, Ignacio. (2016). La concepción de los Patrimonios Culturales y Naturales desde el Pensamiento Complejo. Trabajo de Grado. Maestría en Investigación Integrativa. Multiversidad Mundo Real Edgar Morín, A.C. México.

Morín, Edgar. (1998). Introducción al pensamiento complejo. Gedisa. Francia. Morín, Edgar. (2002). La Cabeza bien puesta. Ediciones Nueva Visión. Argentina. Mosonyi, Edgar. (2009). Balance general de los diez años del proceso bolivariano: pueblos indígenas. Revista Venezolana de Economía Ciencias Sociales. Volumen 15. Número 1. Venezuela (Pp.155-172).

Mosonyi, Esteban. (2012). Identidad Nacional y Culturas Populares. Fondo Editorial Fundarte. Serie Identidad Nacional. Venezuela.

Nicolescu, Basarab. (1996). La transdisciplinaria manifiesto. Edición 7 saberes. México.

Pérez, Ernesto. (2003). Para pensar en la formación del docente venezolano del siglo XXI. Revista de Teoría y Didáctica de las Ciencias Sociales, 8. Venezuela (Pp. 189-208).

Pupo, Rigoberto. (2014). La educación, crisis paradigmática y sus mediaciones. Sophia, Colección de Filosofía de la Educación. Volumen 17. Ecuador. (Pp. 101-119).

República Bolivariana de Venezuela. (2009). Ley Orgánica de Educación. Gaceta Oficial 5929. Venezuela.

Ricoeur, Paul. (1965). Hermenéutica de los símbolos y reflexión filosófica. Universidad de Chile. Chile.

Rodríguez, Milagros. (2017). Currículum, educación y cultura en la formación docente del siglo XXI desde la complejidad. Revista Educación y Humanismo. Volumen 19. Número 33. (Pp. 425-440). http://dx.doi.org/10.17081/eduhum.19.33.2654 consulta: 9/11/2017.

Rodríguez, Salvador. (2012). Postmodernidad, valores y educación. Revista Ciencias de la Educación. Volumen 22. Número 38. Venezuela. (Pp.170182). 
Ruiz, Carlos. (2008). La Universidad venezolana en una época de transición. Universidad Pedagógica Experimental Libertador-Instituto Pedagógico de Barquisimeto.

Disponible en: http://www.ucla.edu.ve/dac/compendium/compendium7/Epoca\%20de\%20Tr ansicion.htm consulta: 12/12/2017.

Santos, Boaventura. (1998). Por una concepción multicultural de los derechos humanos. Universidad nacional Autónoma de México. México.

Santos, Boaventura. (2002). Hacia una concepción multicultural de los derechos humanos. El otro derecho. Volumen 28. Bogotá. (Pp. 59-83).

Santos, Boaventura. (2003). Crítica de la Razón Indolente Contra el Desperdicio de la Experiencia. Volumen I. Para un Nuevo Sentido Común: La Ciencia, El Derecho y La Política En La Transición Paradigmática. Editorial Desclée De Brouwer, S.A. España.

Uzcátegui, Fernando. (2007). Análisis de la evolución de las políticas públicas en comunidades indígenas venezolanas (1836-1959). Revista Venezolana de Ciencia Política. Volumen 32. Venezuela (Pp.11-20).

Villalón, María. (1994). La educación para indígenas en Venezuela: Una crítica razonada. Documento de Trabajo No. 9. Centro Venezolano de Investigaciones en Antropología y Población (CEVIAP). Venezuela.

Villalón, María. (2011). Lenguas amenazadas y la homogeneización lingüística de Venezuela. Boletín de lingüística, XXIII (35-36). Venezuela. (Pp. 143-170). 